\title{
Social Autonomy and Political Integration: Two Policy Approaches to the Government-Nonprofit Relationship since the 18th National Congress of the Communist Party of China
}

\author{
${ }^{1}$ Party School of Zhejiang Provincial Committee of the Communist Party of China, Hangzhou, Zhejiang, China, E-mail: \\ 67923702@qq.com \\ ${ }^{2}$ Indiana University School of Public and Environmental Affairs, Bloomington, Indiana 47405, USA, E-mail: \\ qunwang@indiana.edu. http://orcid.org/0000-0001-7592-9824.
}

\begin{abstract}
:
Since the 18th National Congress of the Communist Party of China, the party-state has established a number of policies on social organizations. Some policies are complementary, whereas some seem to be contradictory. These policies are associated with two policy approaches. The first is socially oriented, allowing social organizations the opportunity for autonomy and encouraging capacity-building. The second is political integration mainly through party-building in social organizations. The two approaches do not exist alone or in isolation. Intertwined they indicate that the Chinese party-state has begun to institutionalize an integrative control mechanism to maximize the utility of social organizations in prioritized fields of work.
\end{abstract}

Keywords: government-nonprofit relationship, social organizations, NPO, social autonomy, political integration, nonprofit policymaking, national party congress

DOI: $10.1515 / \mathrm{npf}-2017-0029$

\section{Introduction}

The government-nonprofit relationship in China has received extensive attention since the late $1980 \mathrm{~s} .{ }^{1}$ Civil society research has focused on the growing number of nonprofit organizations (NPOs) and their implication for the democratization of this transitional authoritarian regime (e. g., Chamberlain 1998). Realizing the decisive role of the Chinese government in shaping the nonprofit sector, some scholars integrated this Western notion with concepts such as "state-led civil society" (e. g., Frolic 1997). Another group of literature found that Chinese NPOs were largely created in a top-down manner and that they lacked independence, served as government appendages with exclusive access to financial and informational resources, and enjoyed a monopolistic representation of their interests (e. g., Unger and Chan 1995). Therefore, they believe that corporatism is a more accurate theory than is civil society in the case of China.

International experience shows that there can be diverse government-nonprofit relationships within one state, ranging from adversarial to collaborative (e. g., Najam 2000; Young 2000). Recent China scholarship has begun to acknowledge and address such diversity and has proposed alternative theories. Kang and Han (2008) coined the term "graduated control" under which the Chinese government differentiated its control in consideration of NPOs' capacity to challenge the state and the value of public services they provide. Spires (2011) concluded that Chinese local governments and grassroots NPOs can coexist on a "contingent symbiosis" based on mutual need and suspicion. As NPOs became able to "negotiate the state" with their own niches appreciated by the state (Saich 2000), Teets (2013) detected "consultative authoritarianism" that incorporated certain elements of pluralism in some regions in China.

Although this research stream offered useful perspectives, it did not fully capture two policy approaches to at least certain NPOs that emerged in the past decade. First, the government shifted its policy framework for NPOs from passive response to proactive empowerment by promoting social autonomy and capacity-building. Second, the government injected political integration through party-building in NPOs, intending to standardize and expand the leadership of the Chinese Communist Party (CCP) in the nonprofit sector. The two policy approaches were formalized at two convocations of the National Congress of the Communist Party of China 
(zhongguo gongchandang quanguo daibiao dahui; hereafter the National Party Congress) (the 17th, 2007-2012; and the 18th, 2012-2017). The 18th National Party Congress was of particular importance because, in its aftermath, the party-state issued a series of legal and administrative documents to institutionalize new policy initiatives. A central norm for nonprofit policy and management that was previously lacking (Wu and Chan 2012) began to emerge.

We argue that the two policy approaches show China's transformation from a pragmatic nonprofit policymaking practice toward a more utilitarian practice. That is, different from shopping at policy venues in the past (see Pralle 2003 for a discussion on policy venues and policy change), the CCP incrementally recognized the importance of nonprofit policymaking and learned how to categorize, calculate, and institutionalize its relationship with NPOs. Local policy innovation is still allowed, but it now follows clarified guidance from the central party-state administration. We address three questions and structure the article in this order as well: First, how has the nonprofit policy evolved at the National Party Congresses? Second, how do we understand the two nonprofit policy approaches since the 18th National Party Congress? Third, what are the combined implications of the policies associated with the two approaches for the government-nonprofit relationship in China? To answer these questions, we apply a discourse analysis to the National Party Congresses and the legal and administrative documents in the aftermath of the 18th National Party Congress.

\section{The 18th National Party Congress and Social Organizations}

The National Congress of the Communist Party of China is effectively the highest body in the country. Despite irregularity in the early days, since 1987, the National Party Congress has been held every five years around October. Delegates to the National Party Congress are formally selected by the provincial-level party committees, and the selection process is screened and supervised by the CCP Central Organization Department. The 18th National Party Congress drew together 2,270 delegates from the party's 82.6 million members as of 2012. During these week-long events, delegates are required to review the General Secretary's report, elect candidates to senior party positions, and decide on amendments to the CCP Constitution. Several months preceding the National People's Congress and Chinese People's Political Consultative Conference, the National Party Congress lays out the policy agenda to be discussed. In the four years following the national assembly, the CCP Central Committee meets at least once a year at a plenum. Communiques and reports from these convocations and plenums are worthy of vigilant care and attention. As Delury (2008) noted, linguistic nuances of the CCP signal shifts in power or policy with great predictability. Indeed, each National Party Congress is a critical juncture for discourse analysis.

In the decade after the Cultural Revolution, civic organizations (minjian zuzhi, which was what the NPOs were named before 2006) flourished because of the relaxed political and social environment. The government applied ad hoc measures to civic organizations because of the absence of standard and consistent registration and management measures (Yan 2007). Immediately after the Tiananmen Incident in 1989, the government enacted the Regulations on the Registration and Management of Social Associations and launched a campaign of reregistration, clearance, and rectification.

It was not until the 14th National Party Congress (1992-1997) that the CCP began to discuss issues related to civic organizations. For example, the Third Plenum of the 14th National Party Congress passed a resolution that required the government to "fulfill the role of industry associations and chambers of commerce" for economic development. In 1997, the 15th National Party Congress proposed that the government should "cultivate and develop social intermediary organizations." Social intermediary organizations (shehui zhongjie zuzhi) include charitable intermediary organizations, economic intermediary organizations, public service institutes (shiye danwei), civic non-enterprise units, and so on (Yang 2011). To some extent, this term denotes the idea that these organizations exist outside rather than within society. Five years later, the 16th National Party Congress, for the first time, raised the issue of party-building in social associations and social intermediary organizations. This period of time showed that the government's understanding and positioning of civic organizations were narrow and largely limited to facilitating the economic development and social stability.

The term "social organization" first appeared in the communique of the Sixth Plenum of the 16th National Party Congress in 2006. This plenum regarded social organizations as an important component of the Harmonious Society - a political discourse endorsed by the CCP General Secretary at that time (see Delury 2008 for a discussion). The 17th National Party Congress, convened one year later, officially replaced the term "civic organization" with "social organization," which covered all types of registered NPOs, placed social organization management under the work of improving people's livelihood, and called for implementing "the work of party-building in ... new social organizations." The 18th National Party Congress further elaborated and expanded the policy objectives for social organizations: improving people's livelihood, strengthening and in- 
novating social governance, and innovating and advancing the work of party-building. First, it urged the party to create a "modern social organization system" in which social organizations "are separate from the government ... and self-govern in accordance with the law"; it also noted that social organizations and the government should "operate with clearly defined rights and responsibilities." Second, it required the party to "improve its provision of public service" and to "guide social organizations for healthy and orderly development." Third, it prompted the party to "intensify the work of party-building in nonpublic economic organizations (feigongyou jingji zuzhi) and social organizations."

The brief discourse analysis of the most prominent cyclical political events in China shows the CCP's (dis)continuity in nonprofit policymaking. On the one hand, social organization management has been an increasingly important consideration of the party-state's work. On the other hand, the CCP has shifted the function of social organizations from economic development coordination to livelihood improvement. This should be considered as a major policy reorientation that will result in subsequent policy change. Moreover, it shows the government's incremental institutionalization of social governance. More utilitarian measures were taken to enlarge the base of social organizations to be tolerated and encouraged. Direct administrative embeddedness of incumbent and recently retired party-state officials was scheduled to be replaced by political integration through party branches and activities. A careful look into this policy framework can help us understand the two intertwined policy approaches. Generally speaking, one is to promote social autonomy and capacity of social organizations, and the other is to politically integrate them into the party system.

\section{Promoting Social Autonomy and Capacity of Social Organizations}

Realizing its limitation in coping with the social and environmental problems following the country's rapid economic development, the Chinese government gradually incorporated social organizations into the arenas of social governance and provision of public services. However, rigid policies inhibited social organizations from developing their capacity as public service providers. The 18th National Party Congress signaled the party's plan to cautiously allow social autonomy and capacity-building for social organizations in the hope of utilizing their resources and expertise to mitigate the government's budgetary constraints. Here, social autonomy refers to decreased direct government involvement and increased self-governance in social organizations. The following subsections summarize the relevant policies.

\section{Administrative Separation of Industry Associations and Chambers of Commerce}

Industry associations (hangye xiehui) and chambers of commerce (shanghui) are business associations that are supposed to represent corporate and business interests in relation to the state, to municipalities, to the market economy, and to society in general (Zhao, Wang, and Thomas 2016). Early research revealed that business associations were usually created by the initiatives of government and party officials and functioned as extended governmental arms (Foster 2002). Often, the government dominated the management of these organizations and compromised their role as communicators on issues of interest between their assigned constituencies and the state (Unger 1996). By the end of 2014, there were about 70,000 business associations in China (Gan 2015). Because of their importance in economic and industrial development, the government prioritized the adjustment of its relationship with business associations.

In 2013, the National Development and Reform Commission and the Ministry of Civil Affairs (MCA), with other relevant ministries, started to draft the Overall Plan for the Separation of Industry Associations and Chambers of Commerce from Administrative Agencies (hereafter the Separation Plan). The Separation Plan intended to conditionally restrict party-state officials from taking either full-time or part-time jobs in business associations, which in turn was expected to lead to better representation of interests. Through pilot experiments in 2014, the government tested separation programs in some cities and provinces. As experience accumulated, the CCP Central Committee and the State Council jointly issued the official Separation Plan in 2015. It stated that "following the requirement of de-administration (quxingzhenghua), the interest chain between [the government and] industry associations and chambers of commerce should be cut off" (Section 1.2). Section 3.3 noted that, in 2018, business associations would no longer receive financial support from the government. Instead, the government would purchase their services. Until that time, their annual funding would decrease gradually. Initially, the work of separation was scheduled to be completed in 2015, but the Separation Plan postponed the deadline to the end of 2017.

It's worth noting that administrative separation is required not only for business associations. In 2016, the CCP Central Committee and State Council also jointly issued the Opinions on Reforming the Social Organization Management System and Promoting the Healthy and Orderly Development of Social Organizations (hereafter the 
Reforming Opinions). This document, in principle, restricted party-state officials from taking jobs in all social organizations.

\section{Government Purchasing of Public Services}

Government purchasing of public services from business associations is neither new nor unique. Because the highly centralized system for providing public services became unable to meet people's needs, Beijing, Shanghai, Shenzhen, and some other major cities began outsourcing public services to NPOs in the 1990s. The process, however, was not always fair and transparent. Zhao, Wu, and Tao's (2016) interviews with service NPOs and government officials showed that the government preferred to purchasing services from NPOs with close political connections. Wang (2018) noted that the government's policy agenda could also be a deciding factor for service contracts.

As government purchasing of public services became increasingly common, the State Council promulgated the Guiding Opinions on Government Purchasing Services from Social Forces in 2013, which was the first step to standardize such practices nationwide. In subsequent years, the MCA, the Ministry of Finance, and some other ministries issued a series of directives, such as the 2014 Notice on Supporting and Standardizing the Undertaking of Government Purchased Services by Social Organizations and the 2016 Guiding Opinions on Supporting the Cultivation and Development of Social Organizations through Government Service Purchasing. The extensive policymaking on government service purchasing has shown the government's inclination to withdraw from providing certain public service and to use contracts as incentives to cultivate and develop NPOs it trusts to complement its own work. Although it may remain a difficult endeavor for NPOs lacking political connections, there is positive evidence that the government follows market or quasi-market methods in making contract decisions (e. g., Jing 2015). In addition, some cities and provinces have drafted local government service purchasing measures to detail the contracting procedure and contractee qualification.

\section{Local Nonprofit Policy Innovation}

The government's policies for service purchasing indicate a two-fold purpose. One is to contract out certain public services, and the other is to improve the capacity of social organizations. In fact, various local governments started to adjust their policies on social organization registration and capacity-building around the time of the 18th National Party Congress. On the one hand, the central government's previous lack of a clear policy norm prevented local governments from seeking policy guidance to deal with NPOs. On the other hand, it left room for local governments to experiment with nonprofit policies, which in turn encouraged NPOs to be innovative. For example, as early as 2011, the Beijing Municipal Government exempted social organizations working on economic development, social welfare, charity, and public services from the so-called "dual management system" that had been effective since the end of the 1980s—-that is, all NPOs had to obtain sponsorship from a government agency before they filed a social organization registration request with the civil affairs department (Simon 2013). Under the dual management system, the registration was notoriously difficult because often the government agencies did not want to bear any political responsibility for supervising a social organization. Thus, Beijing's policy change was a positive move. It also showed the government's belief that NPOs working on these issues were the least politically antagonistic. In 2012, Guangdong Province followed suit to exempt even more diverse NPOs from the dual management. The 2016 Reforming Opinions confirmed that social organizations working, for example, on poverty alleviation, welfare for disadvantaged groups, medical care, and education could directly register with the civil affairs department (Section 5.1).

Meanwhile, some local governments either set up supporting organizations (zhichixing zuzhi, e. g., incubator, accelerator) or designated existing organizations (e. g., NPI in Shanghai, and Amity NGO Development Center in Nanjing) to facilitate the initiation and growth of social organizations, in particular social service NPOs. These supporting organizations are largely the result of the policy of diffusion that originated in Shanghai, the city that first experimented with venture philanthropy. Although hardly any national policies directly regulate such local policy innovations, our visit to a municipal social incubator informed us that, in the near future, we can anticipate the formation of numerous such supporting organizations at local levels throughout the country. These policies have accelerated the registration of social organizations. According to the 2017 China Statistical Yearbook, more than 50,000 social organizations registered annually from 2013 to 2016, about 2.5 times the number in the preceding five years. Many grassroots NPOs that were not able to register in the past could register after the 18th National Party Congress. 


\section{Controlling Social Organizations through Political Integration}

While promoting their complementary role, the Chinese party-state changed administrative embeddedness to political integration by party-building in NPOs. In some sense, political integration is a move toward a less direct yet stricter control. This policy change was formed neither overnight nor suddenly after the 18th National Party Congress. However, recent nonprofit policymaking was intended to explicitly institutionalize political integration into the new policy framework. These policies as a whole indicated that the party-state had begun to rethink how to define its role in relation to NPOs and how to position them in society. As a result, we can observe how the party-state clarified vague bottom lines and emphasized party-building and CCP leadership in NPOs over the past decade. The following subsections review the relevant policies.

\section{Continued Administrative Absorption of Society and Graduated Control}

Kang and Han (2007) explained the dynamics between the government and the NPOs through the lens of administrative absorption of society. On the one hand, the government constrained the constituents from challenging the government through nongovernmental means. On the other hand, it expanded social governance to meet the needs of the constituents. The government did not support all social organizations equally after the 18th National Party Congress. In fact, it continued to apply graduated control (Kang and Han 2008). For example, in the 2016 Reforming Opinions, the government confirmed that, in principle, it would maintain the dual management system and require the supervisory agencies to carefully review social organization registration requests (Section 5.2). As mentioned earlier, exemptions were granted only to certain social organizations, not all social organizations. For the overseas nongovernmental organizations (ONGOs), the government detailed the regulations in the Law of Administration of Activities of Overseas Nongovernmental Organizations in the Mainland of China (hereafter the ONGO Law) in 2016. The ONGO Law stipulates that ONGOs can "conduct activities beneficial to the development of the public welfare in fields such as economy, education, science, culture, health, sports, environmental protection and for areas such as poverty alleviation and disaster relief" (Article 3), and "must not engage in or fund for-profit activities or political activities, and must not illegally engage in or fund religious activities" (Article 5). The policies exhibited the government's intention to orient NPOs toward public welfare.

While acknowledging the continuity of graduated control, we argue that the recent nonprofit policymaking justifies two modifications to this control mechanism. First, the government now pays increased attention to the utility of NPOs in providing public services. Second, the level of control is to be more the strength of the party in the NPOs, and less the severity and diversity of the administrative measures used.

\section{Political Integration through Party-Building}

Through party-building within social organizations, the CCP has integrated social organizations into its political regime and has increased its role of linking the state and the society. The 2016 Reforming Opinions pointed out that one of the functions of social organizations is to enhance and expand the CCP's "ruling foundation" (zhizheng jichu) - the people, organization, and theory that justify and support the rule of the CCP. This document indicated that the party-state regarded social organizations as political instruments, preventing them from becoming sources of pluralistic values. It further required the CCP to advance the work of creating party branches in social organizations and fulfill its role of core political leadership (Section 2.2).

The Reforming Opinions reiterated the CCP's previous nonprofit policies as well. In 2015, the CCP Central Committee issued the Interim Opinions on Strengthening the Party-Building in Social Organizations (hereafter the Interim Opinions), which was preceded by the 2000 Opinions on Strengthening the Party-Building in Social Associations. The titles alone indicate that the party's reach had expanded from one type of social organization to all types. The Interim Opinions regards social organizations as an important field of party work and mass work where grassroots party branches should be established (Section 1.1). In 2016, the MCA promulgated the Notice on Issues Related to Party-Building at the Time of Social Organization Registration (hereafter the Party-Building Notice). The Party-Building Notice mandated that new social organizations submit a "Letter of Commitment for Party-Building" to the civil affairs department (Section 1). In fact, since the 18th National Party Congress, party-building has routinely been an important measure for social organization evaluation. In order to guide the work of party-building and CCP leadership in social organizations, many local governments have formed specialized working committees. The names of those committees vary, although a common feature is that they have become a permanent body within the party system and advocate CCP leadership in nonprofit manage- 
ment and policymaking. One of the author's data and fieldwork show that the majority of social organizations have already established or co-established party branches in Zhejiang Province.

\section{Hub Social Organizations}

Under the leadership of these working committees, some local governments explored a more "decentralized" coordination mechanism, represented by the "hub social organizations" (shuniuxing zuzhi) in Beijing. In 2009, the Beijing Municipal Government issued the Temporary Measures on the Work of Forming City-Level Hub Social Organizations (hereafter the Beijing Hub Measures). In terms of their type, nature, and business, the Beijing Hub Measures defined hub social organizations as social organizations that are designated by the Municipal Leading Group for Social Construction that politically bridge the CCP and the society, that are leaders in a particular business, and that have been authorized to act as supervisors of other social organizations (Article 2). A prerequisite for the hub qualification was the existence of a well-organized party branch (Article 4.3). In the same year, Beijing designated ten citywide hub social organizations, for example, the Labor Union, the Youth League, the Women's Federation, and the Red Cross Association. As of 2017, Beijing had 51 citywide hub social organizations supervising more than 30,000 social organizations (The Beijing Municipal Government Office of the Work for Social Construction 2017). Guangzhou, Shanghai, and some other cities also started to experiment with hub social organizations in their respective jurisdictions.

The administrative "decentralization" of certain supervising and managerial work in hub social organizations is, to a large degree, superficial because all hub social organizations are government-organized, and some of them are public service institutes in nature. They form an additional layer between the government and NPOs, which probably is not easy for the latter to deal with. Their primary responsibility is to lead and control; their secondary responsibility is to guide and help (Ma 2014). Many NPOs, even when qualified for bidding and applying for government service contracts, still have to do so through a hub social organization or in collaboration with a hub-affiliated social organization (ibid.).

\section{Discussion and Conclusion}

In the course of reviewing the nonprofit policy institutionalization at the 18th National Party Congress and its aftermath, this article discusses the Chinese party-state's two policy approaches to the government-nonprofit relationship. The two approaches intertwine the promotion of social autonomy and capacity of social organizations with control through political integration. Although the policies associated with each approach may be seemingly contradictory, in the long run, they are more likely to reinforce each other, rather than compromise the policy framework and result in ambivalent implementation. NPOs, especially those founded civically, may have mixed views when faced with the new policies. While benefiting from increased government tolerance, they may have to become more politically embedded in the party system. It remains to be seen if party-building will become an isomorphic pressure in the nonprofit sector.

The two policy approaches do not guarantee a partnership between the government and NPOs. Granting NPOs autonomy and separating them from administrative agencies are not done to create an independent nonprofit sector. The theory of dependent autonomy may continue to apply (Lu 2008). As stated in the Reforming Opinions and elsewhere, the CCP intended to incorporate the nonprofit sector into its ruling foundation, through which authoritarian resilience (Nathan 2003) endures. Under such formal institutional arrangement, a stronger ruling foundation is aimed at enhancing the political status quo. Therefore, it is reasonable to allow social autonomy and capacity-building to certain NPOs in order to maximize their expected utility. Considering the tradition of the United Front (tongyi zhanxian), it has been a long-term strategy of the CCP to contain and connect the interest and ideology of different groups and professions. The political integration of society through party-building is likely to be a process that is parallel to the administrative absorption of society through social governance. Because the CCP now regards the nonprofit sector as an integral part of its ruling foundation, we can expect the CCP to acknowledge NPOs' political status. The 19th National Party Congress corroborated this point.

The report to the 19th National Party Congress, which convened in 2017, signaled greater policy opportunities for NPOs, in addition to confirming the policies laid out in the 18th National Party Congress. The report stated that the party-state shall "advance the development of wide, multilevel and institutionalized consultative democracy, and adopt a coordinated approach to promote consultations carried out by ... social organizations" (Section 6.3). Moreover, the report noted that, in the area of environmental protection, the party-state shall "establish an environmental governance system in which government takes the lead, business enterprises assume the main responsibility, and social organizations and the public participate" (Section 9.3). These new initiatives 
form a dramatic comparison with the decision-making for the controversial megaproject-Three Gorges Dam, for which the government stifled voices from NPOs and the public (Lieberthal and Oksenberg 1988). Although previous research has documented successful environmental and other policy advocacy by Chinese NPOs (e. g., Teets 2013; Yang 2005), the 19th National Party Congress indicate a procedural rather than contingent policy consultation style in the future. It is too early to evaluate the new policies at this moment. One thing for certain is that the two policy approaches will remain relevant in explaining nonprofit policymaking in the aftermath of the 19th National Party Congress.

\section{Acknowledgements}

The authors wish to thank Beijing Yifang Foundation for its financial support. Qun Wang wishes to thank Beijing Yifang Foundation for the Jinge Fellowship.

\section{Notes}

1 In this article, the term nonprofit organizations (NPOs) refers to registered nonprofit organizations, and the term grassroots NPOs refers to nonprofit organizations that are unregistered or registered as for-profit businesses with the bureau of industry and commerce (gongshangju). In today's China, NPOs are called "social organizations," which comprise three types of NPOs, namely social associations (shehui tuanti), social service organizations (shehui fuwu jigou, formerly known as civic non-enterprise units, minban feiqiye danwei, which are comparable to nonprofit social enterprises in the West), and philanthropic foundations (jijinhui). Social associations are largely equivalent to membership associations such as business associations, science and technology associations, professional associations, academic associations, arts and culture associations, and so forth. According to the 2017 China Statistical Yearbook, there were 702,405 social organizations by the end of 2016. Many social organizations originated as government-organized nongovernmental organizations and remain so now. We use "NPOs" and "social organizations" interchangeably, because the latter is the only official term used in recent legal and administrative documents.

\section{References}

Chamberlain, H. 1998. “Civil Society with Chinese Characteristics?.” The China Journal 39: 69-81.

Delury, J. 2008. "'Harmonious' in China." Policy Review 148: 35-44.

Foster, K. W. 2002. “Embedded within State Agencies: Business Associations in Yantai." The China Journal 47: 41-65.

Frolic, M. B. 1997. "State-Led Civil Society." In Civil Society in China, edited by T. Brook and B.M. Frolic, 46-67. Armonk, NY: M.E. Sharpe.

Gan, N. 2015. "Beijing to Cut Its Ties to Trade Associations." South China Morning Post.

http://www.scmp.com/news/china/article/1835512/beijing-cut-its-ties-trade-associations. Retrieved 26 December 2017.

Jing, Y. 2015. "Between Control and Empowerment: Covernmental Strategies Towards the Development of the Non-Profit Sector in China." Asian Studies Review 39 (4): 589-608.

Kang, X., and H. Han. 2007. “Administrative Absorption of Society: A Further Probe into the State-Society Relationship in Chinese Mainland." Social Sciences in China 2: 116-28.

Kang, X., and H. Han. 2008. “Graduated Controls: The State-Society Relationship in Contemporary China." Modern China 34 (1):36-55. Lieberthal, K., and M. Oksenberg. 1988. Policy Making in China: Leaders, Structures, and Processes. Princeton, N]: Princeton University Press. Lu, Y. 2008. Non-Government Organizations in China: The Rise of Dependent Autonomy. New York, NY: Routledge.

Ma, Q. 2014. "Correcting the Development of Hub Social Organizations." Administrative Reform [Xingzheng Caige] 9: 47-49.

Najam, A. 2000. "The Four C's of Covernment Third Sector-Covernment Relations." Nonprofit Management and Leadership 10 (4): 375-96.

Nathan, A. J. 2003. "Authoritarian Resilience." Journal of Democracy 14 (1): 6-17.

Pralle, S. B. 2003. "Venue Shopping, Political Strategy, and Policy Change: The Internationalization of Canadian Forest Advocacy." Journal of Public Policy 23 (3): 233-60.

Saich, T. 2000. “Negotiating the State: The Development of Social Organizations in China." The China Quarterly 161: 124-41.

Simon, K. 2013. Civil Society in China: The Legal Framework from Ancient Times to the "New Reform Era.". New York, NY: Oxford University Press.

Spires, A. J. 2011. "Contingent Symbiosis and Civil Society in an Authoritarian State: Understanding the Survival of China's Crassroots NCOs." American Journal of Sociology 117 (1): 1-45.

Teets, J. 2013. "Let Many Civil Societies Bloom: The Rise of Consultative Authoritarianism in China." The China Quarterly 213: 19-38.

The Beijing Municipal Covernment Office of the Work for Social Construction (beijingshi shehui jianshe gongzuo bangongshi). The Explanation for the Information Disclosure of the Work on Social Organizations 2017. Retrieved 6 March 2018. http://www.bjshjs.gov.cn/2017/1206/7979.shtml.

Unger, J. 1996. “'Bridges': Private Business, the Chinese Government and the Rise of New Associations.” The China Quarterly 147: 795-819.

Unger, ]., and A. Chan. 1995. "China, Corporatism and the East Asian Model." The Australian Journal ofChinese Affairs 33: 29-53.

Wang, Q. 2018. "A Typological Study of the Recent Development and Landscape of Foundations in China." Chinese Political Science Review. https://doi.org/10.1007/s41111-018-0094-2.

Wu, F., and K. Chan. 2012. "Graduated Control and Beyond: The Evolving Government-NGO Relations." China Perspectives 3: 9-17. 
Yan, D. 2007. “The Relationship between the Communist Party of China and Civic Organizations since the Reform and Opening-Up." Modern China Studies [Dangdai Zhongguo Yanjiu] 3: 147-59.

Yang, G. 2005. “Environmental NCOs and Institutional Dynamics in China.” The China Quarterly 181: 46-66.

Yang, Y. 2011. Governance of Covernment Procurement in China [Zhongguo Zhengfu Caigou Zhili Wenti Yanjiu]. Beijing, China: China Financial and Economic Publishing House.

Young, D. R. 2000. “Alternative Models of Covernment-Nonprofit Sector Relations: Theoretical and International Perspectives." Nonprofit and Voluntary Sector Quarterly 29 (1): 149-72.

Zhao, R., Z. Wu, and C. Tao. 2016. “Understanding Service Contracting and Its Impact on NCO Development in China." Voluntas 27 (5): 2229 51.

Zhao, T., L. Wang, and G. M. Thomas. 2016. "Public Policies, Stakeholder Interest, and Nonprofit Development: The Case of Trade Associations in Shanghai, China." Voluntas 27 (5): 2173-98. 